\title{
Is the consumer sleeping or gone away?
}

Received (in revised form): 8 May 2006

\section{Bridget Rosewell}

is Chairman of Volterra Consulting and Consultant Chief Economist to the Greater London Authority. She is responsible for the GLA's Economics Unit, which undertakes analysis on London's transport system, development projects and all aspects of its economic life. Volterra Consulting was established in 1999 to apply novel ideas to business problems and new approaches to economic analysis and forecasting. Prior to this she was Chairman of Business Strategies Ltd, which is now owned by Experian. Bridget is one of the most experienced economists and commentators on the UK economy practising today and has particular experience in both regional economics and planning and development. Bridget is currently heading up a new real estate research venture, which is a joint Volterra and Strutt \& Parker project.

\begin{abstract}
The performance of the UK economy in 2005 was the worst since 1992, as consumer spending growth dropped dramatically putting severe pressure on retailers. This article looks at the reasons for the slow spending growth of 2005 and asks what can be inferred from that about the behaviour of the consumer in 2006 and going forward. A consideration of the strengths of the UK economy and the risks to growth going forward is then presented. Finally, a scenario around a factor important to the medium term retail outlook is considered, namely the impact of the growth in Internet sales on retail sales volumes.
\end{abstract}

\section{Keywords:}

consumer, spending, economy, prospects, scenarios, internet

Journal of Retail and Leisure Property (2006) 5, 226-234.

doi:10.1057/palgrave.rlp.5100024

Bridget Rosewell

Volterra Strutt \& Parker Research 13 Hill Street

London

W1) 5LQ, UK

Tel: + 02084875611

Fax: +020 88786333

E-mail: spresearch@volterra.co.uk

\section{INTRODUCTION}

The performance of the UK economy in 2005 was the worst since 1992. The main cause of this was a dramatic fall in spending by consumers that hit the retail sector hard, particularly in the period from April to December. Why did consumers disappear from the High Street in 2005? Can they be expected back anytime soon? This article offers, from the experience of 2005 , some answers to these crucial questions for retailers and goes on to examine the dangers and the strengths for the UK economy going forward, given what can be learnt about the economy one lives in today.

\section{THE ECONOMY IN 2005}

At the start of 2005 everything was looking rosy for the UK economy. The consensus growth forecast was 2.5 per cent and the Chancellor was 


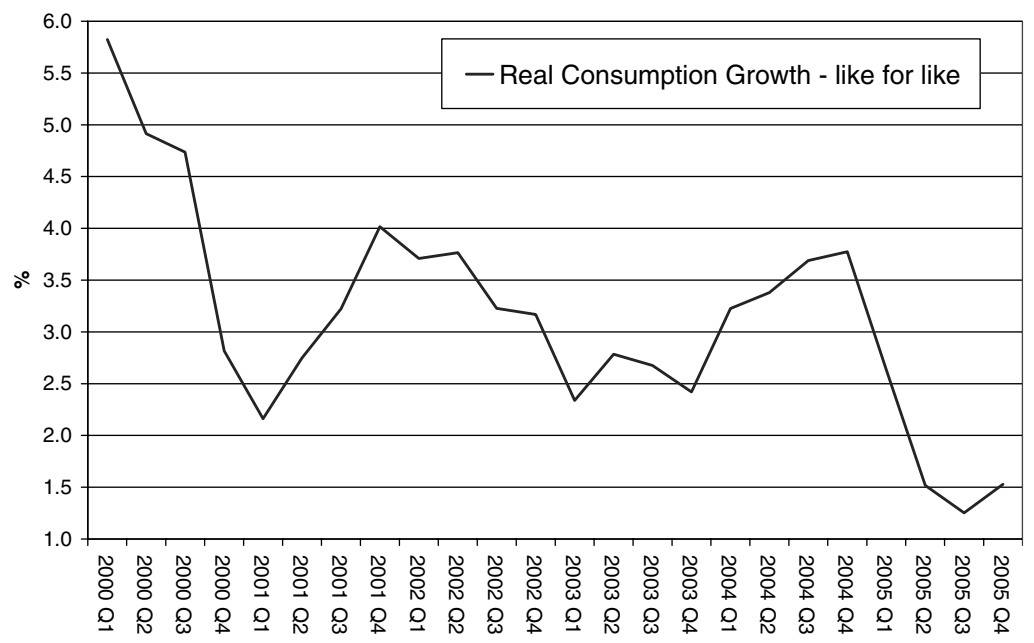

Figure I: Consumption Growth in the UK since 2000 (at constant prices). Source ONS

forecasting very healthy growth of 3-3.5 per cent, well above the long run trend. ${ }^{1}$ The actual outturn was much worse at just 1.8 per cent, the lowest level since the recession of the early 1990s. The Chancellor was predicting growth almost twice as fast as that which actually happened.

Those familiar with the world of economic forecasts might think there is nothing particularly unusual about this, as forecasts of the economy are notoriously unreliable. It is important, however, to understand just why forecasters were so wrong on this occasion, as it helps one to understand if prolonged slower growth is likely, as much of the Eurozone has experienced since $2001,{ }^{2}$ or if the problem was more temporary and a higher rate of growth can be expected to resume.

There were two major, largely unforeseen, factors that caused the poor performance of 2005: the phenomenal rise in oil prices and the collapse in consumer spending. Figure 1 shows the recent history of the growth in consumer spending. The dramatic drop off in 2005 is clear to see.

This unexpected slowdown in consumer spending has made times very tough for retailers. The signs are that despite some pick up, the marketplace remains very tough in 2006. Things may be tougher for some retailers than they are for others, however. Although all sectors experienced a slowdown in 2005, the pain was not equally spread across sectors. As shown in Figure 2, the predominantly food sector did not at any point see falling sales. Understandably, this is the sector with the most stable growth through time, yet even here a swing from increasing growth to falling growth at the end of 2004 can clearly be seen.

The other two sectors had a stronger reaction to the slower spending, with both sectors actually experiencing falling sales at some points in 2005. The textiles and household goods sector went from very strong positive growth in August of 2005 to falling sales by April 2006, a large and rapid turnaround, with negative or near-zero growth persisting until December. Specialised retailing is the sector which is traditionally more volatile and this is reflected by the path of the line in Figure 2: almost a straight line down from the heights of double digit growth in August 2004 to significantly falling sales in the final quarter of the year. Unlike the 


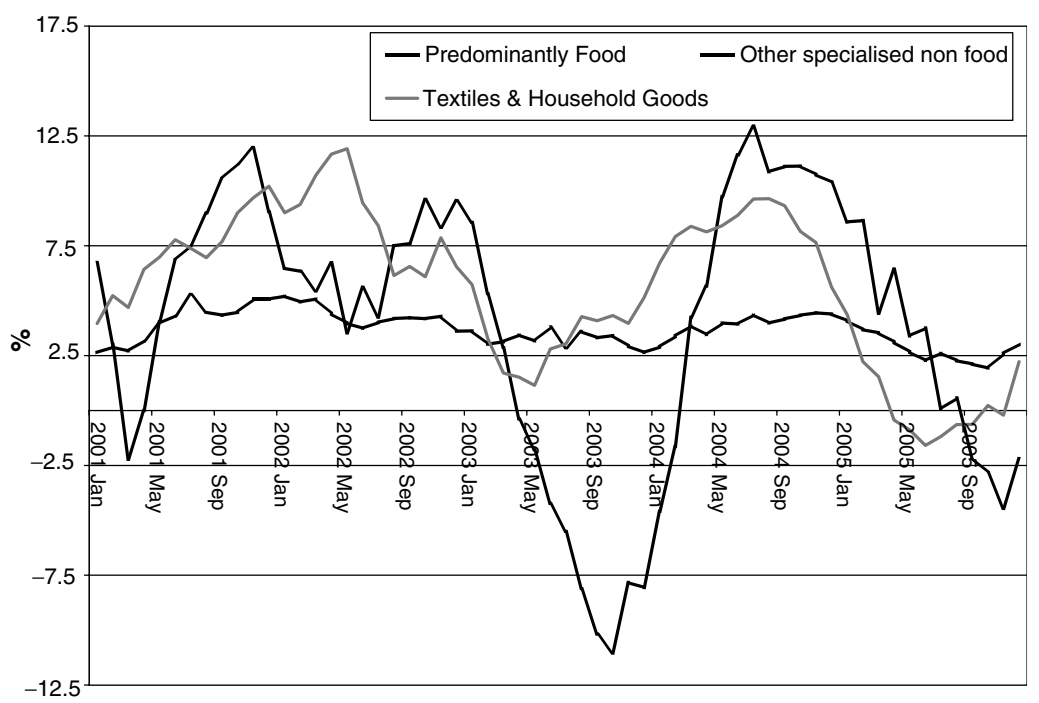

Figure 2: Like for Like Growth in Retail Sales Volumes by Sector (at constant prices). Source ONS

textiles and household goods sector, the specialised sector had not yet returned to positive growth by the end of the year.

The graph is based on figures for the Office of National Statistics (ONS). Other figures from the British Retail Consortium show a similar trend, but paint an even worse picture of the 2005 experience. Arguments about which figures are more accurate thus boil down to whether the experience was bad or very bad. Whichever is believed, there was little good news around for retailers in 2005.

\section{What was behind the slow spending growth?}

While the reasons for the rise in oil prices are all too apparent, why exactly consumer spending in 2005 should drop off is much less clear. Consumer spending in 2004 had been at record levels, and indeed it had been reliably strong since 2001. There was no upsurge in unemployment and although wages were not growing spectacularly, they were ticking up quite nicely. There seemed to be no good reason to expect consumers to suddenly shut up their wallets and refuse to come out and play. In this section, the reasons why such an experience might have come about are examined, with the focus on whether they point to a short-lived downturn or long-term sluggish spending and pain for retailers.

\section{THE SCARY STORY}

First, the scary story. There are always some who are sceptical of the health of the economy and will predict economic Armageddon just around the corner. That, of course, does not mean what they say should not be considered on its merits. The scary stories that have been around and offer an explanation for the downturn that occurred in 2005 predominantly concern two things: consumer debt and house prices. The story goes that there has been a massive and unsustainable binge on credit in the UK combined with the development of an enormous bubble in 
house prices. The slowdown in consumer spending in 2005, is according to this view, just the first sign of stress caused by these terrible problems, the tip of the iceberg. The economy is heading for bankruptcies on a huge scale and an unpleasant dose of negative equity as the housing market crashes, which will stymie spending for a long time to come. The consequences of overindulgence and overoptimism, then, are going to come home to roost in the move forward. From this viewpoint, the slowdown in 2005 is not just a temporary fluctuation, or even a shift to a slower longer term, but still positive, growth path. It is instead a harbinger of doom - the first steps down the slippery slope of economic recession.

A reality check is required. It is true that consumer debt has reached record levels. It is also true that house prices have reached record levels. The important thing, however, is not how much people owe, but whether or not they are in a position to make their repayments. One of the main reasons for the increases in debt levels is that it has become easier to make the repayments on loans as interest rates have fallen during the late 1990s and early 2000s. During the period August 1998 to August 2003, the Bank of England's base rate fell from 7.5 to 3.5 per cent. The interest rates on all consumer loans and mortgages are, in one way or another, linked to this rate of interest. However, people borrowed money, the cost of servicing a given amount of debt was falling almost continuously over this period. When this is borne in mind, it is quite understandable that the amount borrowed has gone up. In addition, stable employment and earnings growth have also helped households afford more debt. The bottom line is that debts have gone up as the cost of serving debt has gone down.

Figures 3 and 4 show some analysis aimed at answering whether or not the level of consumer and mortgage debt is sustainable based on affordability, not alarmism over enormous sounding numbers.

Figure 3 shows an index of affordability of consumer debt through time. This is an index of the proportion of UK earnings taken up by

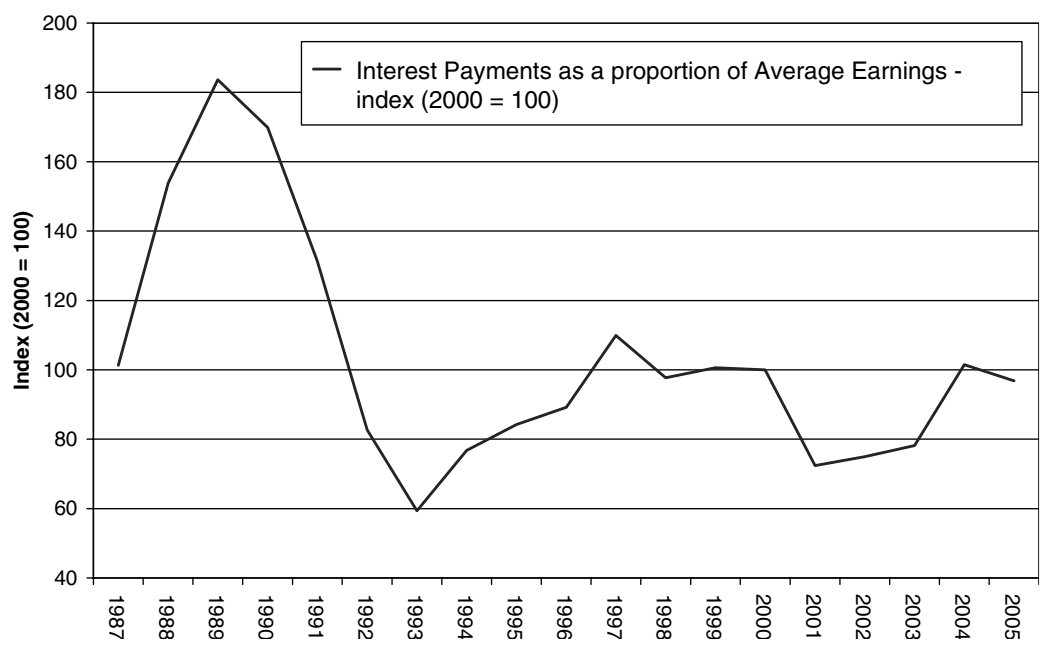

Figure 3: Affordability of Consumer Debt. Source: Calculated using Interest rate (Inter Bank rate), Outstanding debt and Employment data from ONS and Earnings data from Nationwide Building Society (taken from the New Earnings Survey) 


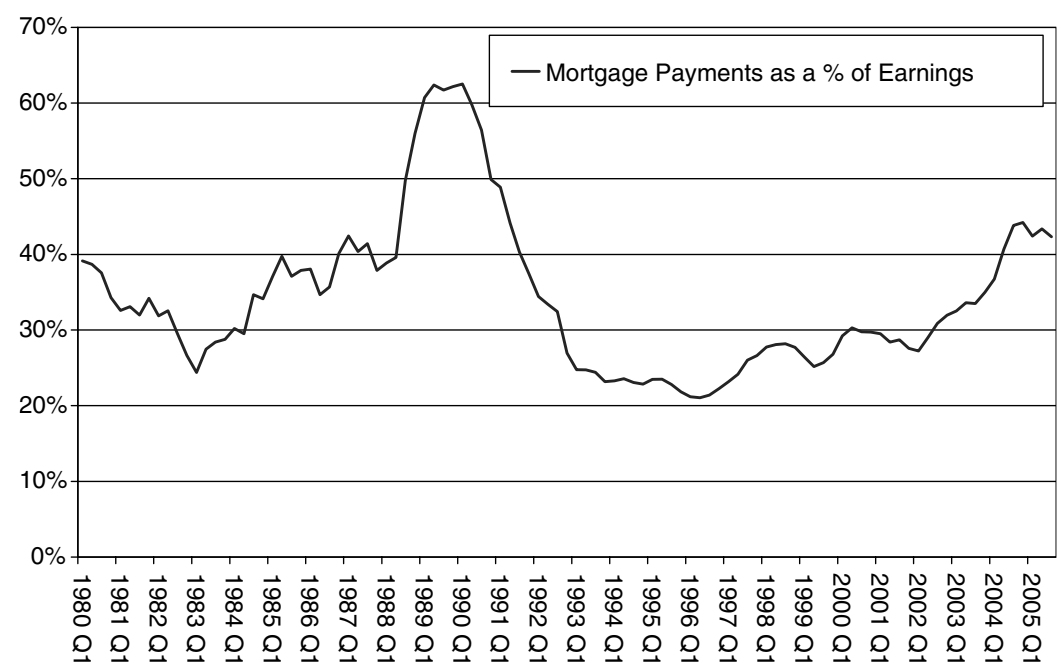

Figure 4: Affordability of Housing. ${ }^{3}$ Source: Nationwide Building Society

paying interest on consumer debt. Consumer debts are on a diverse range of interest rates, meaning the interest rate used in the calculation is not the interest rate that a lot of people will be paying. Nevertheless, the rate used will be linked with all the different rates paid, meaning they all move in the same direction through time. The illustration therefore serves the purpose - to broadly compare affordability now with the past. It is clear that debt has become less affordable into 2005, but the level of affordability is not particularly worrying given what it has been in the past.

Figure 4, which shows the proportion of UK average income required to service a mortgage based on the average house price, gives a similar message. Debt, both consumer and mortgage, has become less affordable in the run up to 2005, but is not showing a dramatic crisis that could prompt house repossessions and bankruptcies on a large scale. As things currently stand, debt is not going to push the economy over the brink. Neither is it going to cause a collapse in the housing market. The large annual rises in house prices that were seen up to 2005 appear to have gone as far as they can go, but what this implies is not a dramatic crash, but a levelling out, which happened in 2005 and will probably continue in 2006. Well so much for the scary story, but what is the real explanation for the sluggish spending of 2005?

\section{THE ACTUAL PICTURE}

Part of a more plausible explanation is apparent in the analysis of affordability of debt presented above. In the run up to 2005, the UK economy saw a pick up in interest rates. The Bank of England base rate went up from 3.5 to 4.75 per cent between mid 2003 and August 2004, staying at that level until August 2005 and affecting consumers. One effect of this is very clearly visible in Figures 3 and 4 - existing debts take up more income as interest rates rise, as shown by the upturn of these 


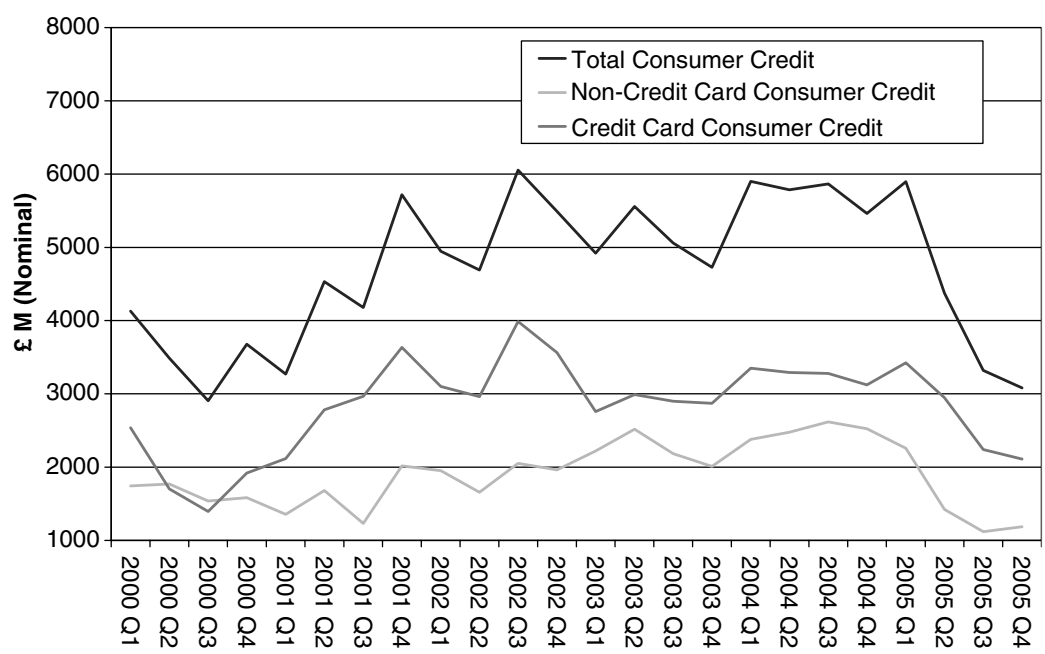

Figure 5: Consumer Credit. Source: ONS

charts between 2003 and 2005. This means people have less money to spend on the high street.

A further effect of higher rates is that people will be less willing to buy on credit or to roll over their existing debts, deferring spending into the future when they either have the cash or have cleared their debts. This is clear from the consumer credit numbers, as shown by Figure 5. Spending on credit, on an upward trend until 2004, fell dramatically in 2005.

Consumer credit over the full year of 2005 was over $£ 6$ billion less than in 2004 according to ONS figures.

A further blow to the level of spending came as people chose to save more of their income in 2005 than they had in 2004. Unsurprisingly, given that people had been borrowing more than ever in 2004, they had been saving less of their income than they did normally. The increase in the saving rate that occurred in 2005 is really a correction back to a more stable trend.

On top of this were the significant increases in oil prices that occurred in the year. Although the economy appears to have weathered these quite well to date, some negative impact will have played a part in the slowdown in consumer spending.

In one respect, the scary story, like most scary stories, carries a grain of truth - debt did have something to do with the slowdown in spending. What happened was not, however, the beginning of a catastrophic cycle of bankruptcies or the bursting of a house price bubble, but rather the result of a managed adjustment by consumers in response to a change in the costs of servicing debt. This combined with a reversion to trend in savings and the oil price shock resulted in slow consumer spending and economic growth.

\section{Looking forward}

The important implication of all this is that things are not set to continue getting worse. The UK economy is not at the jumping off point into a black hole of protracted recession and the downturn should be shallow 
and reasonably short. The answer to the question posed in the title is that consumers have not gone away. How long they will sleep for depends on how much longer it will take people to make up for the spending of the past and clear some old debt. Barring any interest rate hikes or sudden shocks to the economy, 2006 will not be any worse than 2005. In fact, an improvement on 2005 can be expected, on the grounds that as spending was reduced so much last year many people must be coming into the year with a healthier personal balance sheet, making them more likely to spend, at least a bit more than they did in 2005. A quick return to the high levels of spending that occurred prior to 2005 is not going to happen, however, as that fast spending growth was fuelled by fast debt growth allowed by lower interest rates.

All this, of course, comes with the proviso that nothing else goes wrong for the economy. The article now moves on to consider how safe an assumption this is given the strengths of the economy and the potential pitfalls that lie ahead.

\section{REASONS TO BE CHEERFUL}

Despite the fact that the UK economy is coming off its worst performance since 1992, there are still many reasons to be cheerful, and people in other economies who have good reason to be jealous of the UK's current position. Despite some recent increases in unemployment, the UK labour market remains strong with high employment and stable wage growth not enough to spark fears of inflationary pressure, but not too little to worry retailers. In addition, last year the financial markets put in a good performance, boosting the wealth of individuals and companies. External demand for UK produce should also be stronger than in recent times as the prospects for economic growth in the world economy appear to be better than in recent years. One further sign of strength is the current stable level of inflation, particularly given that last year the UK economy experienced a very large oil price shock.

\section{THINGS TO WATCH OUT FOR}

The state of the public finances gives some cause for concern. Over the last three years the government has been running a deficit, as shown by Figure 6. Although this gap appears to have closed towards the end of 2005, most analysts view this as a temporary phenomenon, caused by some large one off receipts. Going forward there is still a gap that must be closed between planned spending and expected receipts. This means either higher taxes or falling spending. Already the government has faced conflict with public sector workers over proposals for pay increases as the Chancellor tries to squeeze spending. Public spending slower than economic growth has been pencilled in for the next spending review period (the three years from 2007/2008), which is particularly worrying as much of the employment growth under Labour has come from the public sector. 


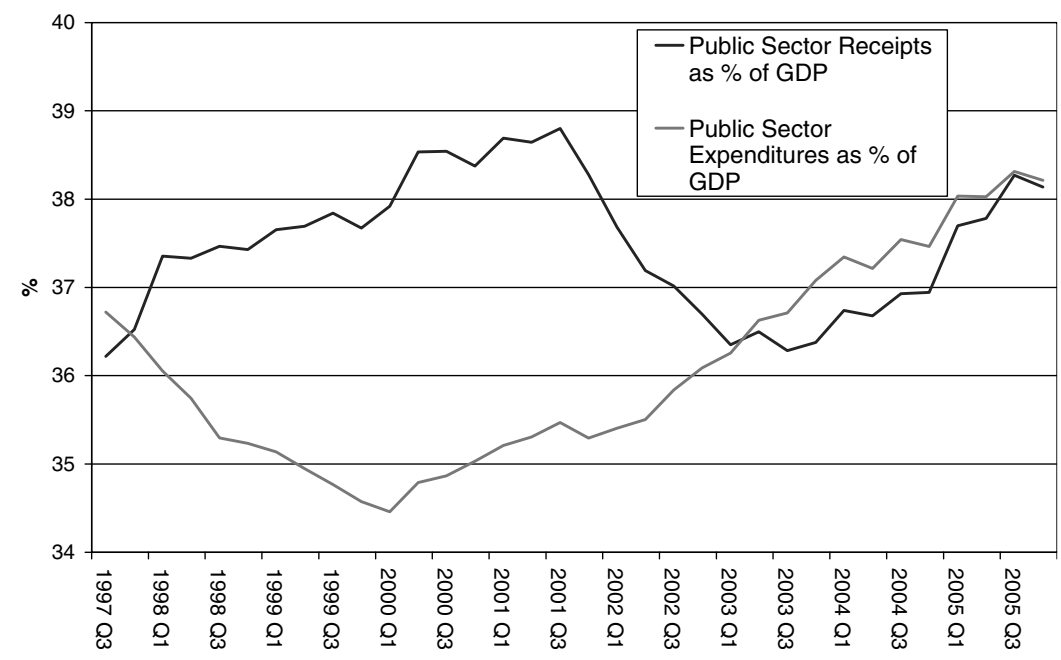

Figure 6: Public Sector Receipts and Expenditures as a percentage of Output. Source: ONS

A further thing to watch out for is inflationary pressure, which could force interest rates up, reducing peoples' disposable income and spending as well as putting up the cost of investment for firms. In the recent past, falling import prices have helped to keep inflation in check. This can't be relied on going forward. Also, the particular type of inflationary pressure matters. Until 2005, pressure to push up prices came mostly from buoyant demand, which is relatively painless to choke — interest rates go up, but only when the economy is doing well and can take the hit relatively easily. Rising prices caused by supply factors, like energy prices, imply raising rates to control inflation regardless of the health of the economy.

These factors indicate that the decision of how to set interest rates is now much harder for the Monetary Policy Committee, something that has been acknowledged by the Governor of the Bank of England. The other thing to note here is that, as discussed, debt is at record levels. This is fine if people can pay their debts. With more debt, however, a small rise in interest rates makes repayment harder. It is reasonable to expect that going forward, consumers will be more sensitive to interest rate rises than in the past, as such rises will have a bigger effect on debt repayments and therefore disposable income. This is one good reason to watch out for inflationary pressures.

\section{Impact of the Internet - will the computers eat all the shops?}

In this final section, the article turns to a much discussed but a poorly understood phenomenon: the impact of the Internet on retail. The value of online spending in the UK was $£ 16$ bn in 2004 according to APACS, the people who monitor credit/debit payments. They have predicted that it will reach $£ 60 \mathrm{bn}$ in 2014 . Predicting this type of event, the emergence of a completely new market, is incredibly difficult, so these numbers should be treated with caution. That said, this does not seem an entirely unreasonable prediction. So what would that imply for retailers if growth were to take place as APACS predict? Figure 7 illustrates the share of 


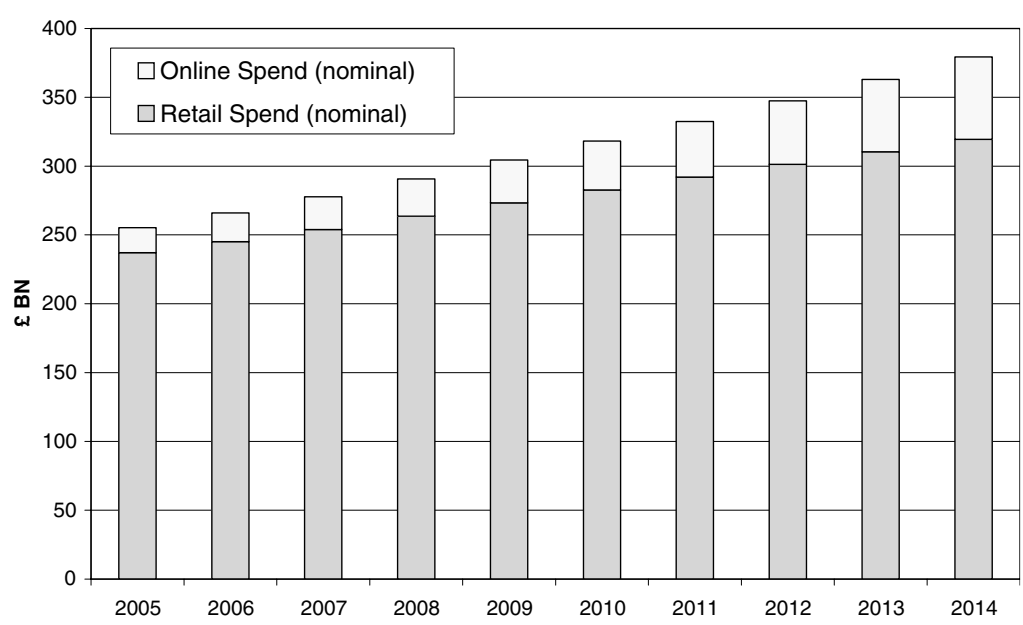

Figure 7: Impact of the Internet on Retail Spending. Source: Calculated using data and forecasts of online spending from APACS, Retail Spending from ONS and Medium Term Consensus forecasts of consumer spending published by the UK Treasury

spending split between traditional retail and online sales, based on some reasonable assumptions regarding the growth of total spending.

The chart shows that retail spending continues to increase despite the growing share of total spending that takes place online. The computers will not eat all the shops, but there will be some impact. This is already apparent, for example, in the case of HMV, a retailer whose market share has undoubtedly been cut by online competition and has subsequently made a loss. Canny retailers are learning from such experience and realising that if their product is easily sold over the Internet, they can take advantage of their brand and be the ones to make the sales, if they get in early enough. Examples are Next, New Look and Argos.

\section{CONCLUSION}

The key conclusion is that the consumer has not gone away and will be around all the way into the future. This does not mean that things will get a great deal easier for UK retailers who, in the most likely outcome, can expect a better 2006 than 2005, but cannot expect to get back to the heady days of 2004. The outlook, however, is very uncertain and contains considerable risk, particularly as it appears that any interest rate rises may hurt more than the in the past and future inflationary pressures, the trigger for interest rate rises, are more uncertain than they have been for many years.

\section{Notes}

1 See UK Treasury (January 2005), Forecasts for the UK Economy: A comparison of independent forecasts, No.213.

2 The notable exceptions being Ireland, Greece and Spain.

3 Mortgage payment as a percentage of average earnings based on a mortgage of $75 \%$ of the value of the average house price at the date shown. 